\title{
1 A mitochondrial genome phylogeny of voles and lemmings (Rodentia: Arvicolinae): evolutionary and taxonomic implications
}

3

4

5 Natalia I. Abramson ${ }^{1 *}$, Semyon Yu. Bodrov ${ }^{1}$, Olga V. Bondareva ${ }^{1}$, Evgeny A. Genelt-Yanovskiy ${ }^{1}$, 6 Tatyana V. Petrova ${ }^{1}$

7

$8{ }^{1}$ Department of Molecular Systematics, Laboratory of Theriology, Zoological Institute RAS, Saint 9 Petersburg, Russia
E-mail: Nataliya.Abramson@zin.ru

All authors contributed equally to this work
* Corresponding author 


\section{Abstract}

Arvicolinae is one of the most impressive placental radiations with over 150 extant and numerous

21 extinct species that emerged since the Miocene in the Northern Hemisphere. The phylogeny of

22 Arvicolinae has been studied intensively for several decades using morphological and genetic methods.

23 Here, we sequenced 30 new mitochondrial genomes to better understand the evolutionary relationships

24 among the major tribes and genera within the subfamily. The phylogenetic and molecular dating analyses

25 based on $11,391 \mathrm{bp}$ concatenated alignment of protein-coding mitochondrial genes confirmed the 26 monophyly of the subfamily. While Bayesian analysis provided a high resolution across the entire tree,

27 Maximum Likelihood tree reconstruction showed weak support for the ordering of divergence and 28 interrelationships of tribal level taxa within the most ancient radiation. Both the interrelationships among 29 tribes Lagurini, Ellobiusini and Arvicolini, comprising the largest radiation and the position of the genus 30 Dinaromys within it also remained unresolved. For the first time complex relationships between genus 31 level taxa within the species-rich tribe Arvicolini received full resolution. Particularly Lemmiscus was 32 robustly placed as sister to the snow voles Chionomys in the tribe Arvicolini in contrast with a long-held 33 belief of its affinity with Lagurini. Molecular dating of the origin of Arvicolinae and early divergences

34 obtained from the mitogenome data were consistent with fossil records. The mtDNA estimates for 35 putative ancestors of the most genera within Arvicolini appeared to be much older than it was previously 36 proposed in paleontological studies.

\section{Introduction}


Reconstructing the phylogeny of a taxonomic group that emerged during the rapid species

39

40

41

42

43

44

45

46

47

48

49

50

51

52

53

54

55

56

57

58

59 diversification is the major challenge in evolutionary biology. When a small number of molecular

markers are considered in the study, unresolved bush-like trees or polytomies are obtained. The subfamily Arvicolinae Gray, 1821 (Rodentia: Cricetidae) consisting of voles, lemmings and muskrats, provide a good example for the research of systematics and taxonomy of fast species radiations within mammals. Arvicolinae is a highly diverse, youngest and fast-evolving group within the order Rodentia. During the rapid explosive radiation and diversification that started in the Late Miocene according to the fossil records, voles and lemmings occupied all types of landscapes within the temperate and cold climate biomes of the Northern Hemisphere. The morphological evolutionary history of the group is perfectly documented using the rich fossil records upon a number of extinct species described. Modern global fauna of Arvicolinae contains 151-162 recent species grouped into 28 genera [1,2], and new species are constantly being discovered and described. Similarly to other taxa that experienced rapid adaptive radiation, phylogenetic reconstruction of this group faces several principal methodological problems, as ecological convergence and homoplasy severely limit the use of morphological traits in phylogenetic analysis.

Phylogeny of Arvicolinae has been explored using both morphological and genetic methods, allowing comparisons of reconstruction from different datasets for further cross-validation. Application of molecular phylogenetic methods resulted in a series of revisions of phylogenetic relationships and taxonomic structure of several genera and species [3-12] and references therein. Reconstruction of Arvicolinae phylogeny using nuclear genes $G H R$ and $L C A T$ demonstrated three successive waves of adaptive radiations in the evolutionary history of the group [7]. The first radiation wave most plausibly took place in Late Miocene and marked the emergence of muskrats (Ondatrini), lemmings (Lemmini and Dicrostonychini) and long-clawed mole voles (Prometheomyini). Second radiation wave is characterized 
61 by a divergence of the ancestors of modern Clethrionomyini. The third radiation wave included

62 formation of the steppe lemmings (Lagurini), mole voles (Ellobiusini) and the richest species group -

63 Arvicolini [7]. The branching order both within the first and the last radiation waves also remained

64 unresolved since all attempts to untangle complex phylogenetic relationships within subfamily were

65 made with the use of only a few mitochondrial or nuclear markers, or the study included an insufficient

66 number of taxa in the analysis $[3,5,7,9,10,12-18]$.

With the upcoming epoch of genomic studies, it is obvious that further breakthrough in the study

68

69 of the extremely complex evolutionary history of the subfamily Arvicolinae can only be achieved by switching from the "gene-centric" approach to the analysis of genomic datasets, yet comprehensive sampling of taxa is also important. Analyses of complete mitochondrial genomes have been successfully used to reconstruct robust phylogenies in many animal groups [19-23] and other. The number of published mitogenomes of voles, lemmings and muskrats is permanently increasing [24-38] and other, and data on nearly one-fifth of the total species diversity (ca. 30 species) is already available.

Though molecular studies during the last decades have considerably extended and refined our knowledge of the pattern and timescale of arvicoline phylogeny, there are important issues that remain to be elucidated. In this study, we were aimed on estimating the phylogeny of Arvicolinae using complete mitogenomes generated using high-throughput sequencing. By significantly increasing the number of newly sequenced mitogenomes representing major tribes of voles and lemmings, we implement the phylogenetic and molecular dating analysis on a dataset consisting of almost all living genera within the subfamily. The following questions were specifically addressed during the study: (1) the order of divergence and interrelationships of taxa within the first, most ancient radiation, (2) the interrelationships of three tribe level taxa Lagurini, Ellobiusini and Arvicolini (3) relative phylogenetic placement of genera Dinaromys Kretzoi, 1955 and Lemmiscus Thomas, 1912, (4) tangled interrelationships of genera 
84 and subgenera in the most speciose tribe Arvicolini, (5) the position of Agricola agrestis Linnaeus, 1761

85 and Iberomys cabrerae Thomas, 1906, and (6) the timing of arvicoline divergences.

\section{Material and methods}

\section{Taxonomic sampling}

Fifty-eight species of Arvicolinae, belonging to 27 genera and all the tribe level taxa, as well as

89 six outgroup taxa were used in this study. Complete mitochondrial genomes for 30 Arvicolinae species

90 were sequenced in the current study (including 15 species belonging to the Arvicolini tribe, one for

91 Dicrostonychini, two for Lagurini, three for Lemmini, six species belonging to Clethrionomyini and 92 three crucial species without stable taxonomic position: Prometheomys schaposchnikowi Satunin, 1901

93 (Prometheomyini), Dinaromys bogdanovi Martino, 1922 and Lemmiscus curtatus Cope, 1868). For 28

94 species belonging to Arvicolini, Ellobiusini, Clethrionomyini, Dicrostonychini and Ondatrini tribes

95 sequences were available in the NCBI database. The detailed information, GenBank accession numbers, 96 and the voucher IDs for new sequences are given in S1 Table. Hereinafter, we use the taxonomic 97 classification following Gromov \& Polyakov [39], Musser \& Carleton [1], Abramson \& Lissovsky [40] 98 with amendments made in result of the current study. 


\section{DNA isolation, NGS library preparation and sequencing}

Muscle tissue samples of fresh specimens were collected between 1996-2019 years and stored in

104

105

106

107 96\% ethanol at -20 degrees Celcius in a tissue and DNA collection of the Group of molecular systematics of mammals (Zoological Institute RAS). Historic specimen of Lemmiscus curtatus (sampled in 1927) was obtained from the collection of the laboratory of theriology (Zoological Institute RAS), see S1 Table for details.

Homogenization of tissues was performed using the Qiagen TissueLyser LT (Qiagen). For the most samples, genomic DNA was extracted using the Diatom DNA Prep 200 (Isogen, Russia) except for the $L$. curtatus museum specimen. To reduce the potential contamination, all manipulations with the $L$. curtatus were carried out in a separate laboratory room isolated from post-PCR facilities, predominantly being used for studies of historic samples from the collection of Zoological Institute. All the working surfaces, instruments and plastics were sterilized with UV light and chloramine-T. DNA from the museum skin sample $(2 \times 2 \mathrm{~mm}$ piece from the inner side of the lip, dissected by a sterilized surgical blade) was isolated using the phenol-chloroform extraction method according to a standard protocol [41]. PCR was prepared using a PCR workstation (LAMSYSTEMS CC, Miass, Russia).

The following ultrasound fragmentation of the total genomic DNA was implemented using Covaris S220 focused ultrasonicator instrument (Covaris). The resulting fragmented DNA was purified and concentrated using paramagnetic bead-based chemistry AMPure XP (Beckman-Coulter) using standard workflow. DNA concentration was evaluated using a Qubit fluorometer (Thermo Fisher Scientific).

NGS libraries were prepared using the NEBNext Ultra II DNA Library Prep Kit for Illumina (New England Biolabs). The resulting PCR products were purified and concentrated using AMPure XP beads (Beckman-Coulter). The concentration of samples was measured using a Qubit fluorometer, and 
quality control of the libraries was implemented using Bioanalyzer 2100 instrument and the DNA High

Sensitivity kit (Agilent). Sequencing was performed on an Illumina HiSeq 4000 system, resulting in pair-

end reads of 75bp. DNA quality was checked with Qubit, the final distribution of lengths of the libraries

adapter content checking was conducted using Bioanalyzer2100 (Agilent). DNA extraction (except the

museum specimen of L. curtatus), library preparation and sequencing were performed using resources

of the Skoltech Genomics Core Facility (https://www.skoltech.ru/research/en/shared-resources/gcf-2/).

\section{Read processing, mitogenome assembly and annotation}

The quality of raw reads was evaluated using FastQC [42], and parts with the quality score below 20 were trimmed using Trimmomatic-0.32 [43]. Bowtie 2.3.5.1 [44] was used to filter reads with contamination. Complete mitochondrial genomes of other Arvicolinae were used as reference sequences. Also, this was made for the museum specimen to enrich reads with mitochondrial DNA.

Nucleotide misincorporation patterns that can often be observed during the studies of ancient or old museum sample DNA as a result of post-mortem DNA damage in reads from L. curtatus were achieved using mapDamage 2.0 [45].

Complete mitochondrial genome was assembled using plasmidSPAdes [46] with default settings.

The resulting contigs were filtered by length, the most similar in size to mitochondrial DNA were selected (size about $16 \mathrm{~kb}$ for mammals). The contigs were annotated using the online-server MITOS [47] http://mitos2.bioinf.uni-leipzig.de/index.py, with default settings and the vertebrate genetic code for mitochondria.

Gene boundaries were checked and refined by alignment against 28 published mitogenome sequences of Arvicolinae (see details in S1 Table). All positions of low quality, low coverage, as well as 
$147 \mathrm{~N}$ manually. Assembled sequences of protein coding genes (PCGs) were checked for internal stops

148 manually. All assembled and annotated mitogenomes have been deposited in GenBank (S1 Table).

\section{Sequence alignment}

The 30 newly obtained mitochondrial genomes were compared with 28 earlier published 151 Arvicolinae mitogenomes mined from NCBI (see accession numbers in S1 Table), including and five mitogenomes obtained by us earlier [48-50]. All mitochondrial genomes were aligned with Mauve (http://darlinglab.org/mauve/mauve.html) in Geneious Prime 2019.1 (Biomatters Ltd.).

In several studies, it has been convincingly shown that protein-coding sequences may have a strong resolving power for inferring phylogenetic interrelationships and divergence time estimates derived from PCG may be quite accurate [22,51,52]. We used this approach, however complete mt genomes will serve as the starting point for further analyses. For the subsequent analyses, the concatenated alignment of 13 PCGs using MAFFT version 7.222 [53] was produced.

Third codon position has previously been shown to bias phylogenetic reconstructions [54]. The phylogeny on a smaller dataset of Arvicolinae turned out to be very poorly resolved with the exception of third codon position [50]. So we masked transitions in 3rd codon position by RY-coding ( $\mathrm{R}$ for purines and $\mathrm{Y}$ for pyrimidines) as described in Abramson et al. [50].

Thus, two datasets were subsequently analyzed - total alignment of 13 PCGs, where all three codon positions were considered (with a length of 11,391 bp) and RY-coded alignment with transitions in third codon position masked. 


\section{Analysis of base composition}

The base composition was calculated in Geneious Prime 2019.1 (Biomatters Ltd.). The strand bias in nucleotide composition was studied by calculating the relative frequencies of $\mathrm{C}$ and $\mathrm{G}$ nucleotides

$(\mathrm{CG} 3$ skew $=[\mathrm{C}-\mathrm{G}] /[\mathrm{C}+\mathrm{G}])[22,55,56]$. Both analyses were calculated using full-length mitogenomes.

The PCG-alignment of 64 mitochondrial genomes was used to calculate relative frequencies of four bases (A, C, G and T) at each of three codon positions in MEGA X [57]. The 12 variables, each representing base frequency in first, second or third position, were then summarized by a Principal Component Analysis (PCA) using the PAST v.4.04 [58].

\section{5}

\section{Saturation tests}

The presence of phylogenetic signal was assessed with a substitution saturation analysis using the Xia test [59] in the DAMBE 7.2.1 software [60] for the whole alignment of the PCG dataset and 13 separate genes following the procedure described by Xia \& Lemey [61], particularly when (a) 1 st and 2nd codon position considered and 3rd position is masked from the alignment, and (b) when only 3rd codon position is included in the analysis. The analysis is based on Index of substitution saturation - Iss, and Iss.c is the critical value at which the sequences begin to fail to recover the true tree).

Once Iss.c is known for a set of sequences, then we can calculate the Iss value from the sequences and compare it against the Iss.c. If Iss value exceeds the Iss.c, we can conclude that the sequence dataset consists of substitution saturation and cannot be used for further phylogenetic reconstruction.

The proportion of invariant sites was specified for tests considered 1st and 2nd codon positions. The analysis was performed on a complete alignment with all sites considered. Additional analysis of saturation for each of the PCG was estimated using R packages seqinr [62] and ape [63]. P-distances were plotted against K81 distances for transitions and transversions of each codon position. 


\section{Phylogenetic analyses}

We used PartitionFinder 2.1.1 [64] applying AICc and "greedy" algorithm, when an analysis is based on the a priori features of the alignment, to select the optimal partitioning scheme for each dataset.

Our analysis started with the partitioning by codon positions within PCG fragments, each treated as a unique partition. For the complete 13 PCG alignment, GTR $+\mathrm{I}+\mathrm{G}$ model was suggested almost for all the partitions except ND6 3rd codon position, for which the $\mathrm{TRN}+\mathrm{I}+\mathrm{G}$ model was selected. For the analyses were performed on both complete and RY-masked datasets partitioned as suggested with PartitionFinder. Trees were rooted by six sequences of Cricetinae: Akodon montensis Thomas, 1913, Peromyscus megalops Merriam, 1898, and four species of hamsters from genus Cricetulus MilneEdwards, 1867 (S1 Table).

Maximum Likelihood (ML) analysis was performed using IQ-TREE web server [65] with 10,000 ultrafast bootstrap replicates [66]. Bayesian Inference (BI) analysis was performed in MrBayes 3.2.6 [67]. Each analysis started with random trees and performed two independent runs with four independent Markov Chain Monte Carlo (MCMC) for 10 million generations with sampling every 1,000th generation, the standard deviations of split frequencies were below 0.01 ; potential scale reduction factors were equal to 1.0; stationarity was examined in Tracer v1.7 [68]. A consensus tree was constructed based on the trees sampled after the $25 \%$ burn-in.

We also conducted ML analysis for each PCG separately (with partitions by codon positions and models supposed with IQ-TREE). Hyperacrius fertilis True, 1894 sequence was excluded from the ND4 211 alignment since this gene was highly fragmented [50]. The mitogenome of Craseomys rufocanus 
212 Sundevall, 1846 (accessed from GenBank) completely lacked the ND6 sequence (S2 Table), so this

213 species was excluded from the analysis for this gene.

\section{Divergence dating}

Divergence times were estimated on the CIPRES Science Gateway [69] with Bayesian approach implemented in BEAST v.2.6.2 [70] using both complete PCG dataset and the one in which the

transitions in the third codon position were masked with RY-coding. Datasets were partitioned according

to the recommendations of PartitionFinder. All site model parameters were chosen for separate partitions

with corrected Akaike's information criterion (AICc) in JMODELTEST 2.1.1 [71]. Eight fossil

calibrations were used (S3 Table). Lognormal prior distributions were applied to all the calibrations with

offset values and 95\% HPD intervals based on first appearance data (FAD) and stratigraphic sampling

downloaded from the Paleobiology Database on 01.12.2020 using the parameters "Taxon $=$ fossil species, Timescale = FAD” $($ S3 Table $)$.

BEAST analyses under the birth-death process used a relaxed lognormal clock model and the program's default prior distributions of model parameters. Each analysis was run for 100 million generations and sampled every 10000 generations. The convergence of two independent runs was examined using Tracer v1.7 [68], and combined using LogCombiner, discarding the first 25\% as burnin. Trees were then summarized with TreeAnnotator using the maximum clade credibility tree option and fixing node heights as mean heights. Divergence time bars were obtained automatically in FigTree v1.4.3 (http://tree.bio.ed.ac.uk/software/figtree/) from the output using the $95 \%$ highest posterior density (HPD) of the ages for each node. 


\section{Results}

\section{Mitochondrial genome assembly and annotation}

We sequenced, assembled and annotated mitochondrial genomes for the 30 new taxa of

Arvicolinae. The mapDamage analysis implemented on the raw reads of Lemmiscus curtatus (S1 Fig)

showed a low variation of deamination misincorporations values. $\mathrm{C}$ to $\mathrm{T}$ misincorporations varied from

10 to $15 \%$, G to A from 10 to $12 \%$ and was equal to the results of similar studies [72]. Since the relative

level of observed misincorporations was not significantly different from the other substitution variants,

the mitogenome of L. curtatus was assembled using the same pipeline as for the rest of taxa.

mammals, contained 13 PCGs, 22 transfer RNAs (tRNA), two ribosomal RNAs (rRNAs), and a non-

243 coding region corresponding to the control region (D-loop). Nine genes (ND6 and eight tRNAs) were

244 oriented in the reverse direction, whereas the others were transcribed in the forward direction. All the

245 assembled mitogenomes contained all the genes listed above, but in some species demonstrated

246 incomplete gene sequences (see S2 Table for details).

247 Mitochondrial genome sequences were deposited in GenBank under accession numbers indicated 248 in S1 Table. In the subsequent analyses, the PCG dataset, containing 11,391 bp was used.

\section{Variation in base composition}

Comparison of base composition calculated using the alignment of full-length mitogenome

251 sequences of Arvicolinae showed that mitochondrial genomes of taxa from tribes Clethrionomyini

$(28.36 \% \mathrm{C})$ and Ellobiusini $(28.7 \% \mathrm{C})$ have the highest GC-content. Arvicolini, Dicrostonychini and 
Lemmini had slightly smaller values: $27.69,28.03$ and $27.77 \% \mathrm{C}$ respectively. Lagurini were found to

254 have the most AT-skewed base composition of mitogenomes: 31.20 and $31.30 \%$ of adenine, respectively

(S1 Table). Lagurini and Arvicolini also demonstrated the highest GC-skew values (-0.32 in both cases).

Ellobiusini and Clethrionomyini occupied an intermediate position in terms of it with -0.33 and -0.34 ,

respectively. Dicrostonychini and Lemmini with equal value -0.35 have the smallest GC-skew values.

The base composition (frequency of the nucleotides A, C, G, and T) was further analyzed at the

three codon positions in the concatenated alignment of PCGs for each species separately (S1 Table). The

12 variables measured for 64 taxa were summarized by a PCA, based on the first two components, which

contributed $73.7 \%$ and $18.8 \%$ of the total variance, respectively (Fig 1). Most of the observed variation

was related to the percentage of base composition in a third codon position. The first component

demonstrated a high positive correlation (0.98) with the percentage of C3 (percentage of cytosine in the

third position) and a high negative correlation (-0.93) with $\mathrm{T} 3$ (thymine in the third position). The second component positively correlated with G3 (0.67) and negatively correlated with A3 (-0.88). Most of the

Arvicolinae formed a compact group on the PCA graph. Among the highly dissimilar to the main group

were almost all Cricetulus species. The two rest outgroup taxa, C. kamensis Satunin, 1903 and Akodon

montensis grouped with Arvicolinae, and A. montensis showed similar base composition to Hyperacrius

fertilis. Among Arvicolinae, the most dissimilar base composition was observed in Mynomes

longicaudus Merriam, 1888, Chionomys gud Satunin, 1909 and Arvicola amphibius Linnaeus, 1758,

showing higher than group average percentage of $\mathrm{T} 3$ and lower than group average percentage of $\mathrm{C} 3$.

The mitochondrial genome of Ondatra zibethicus Linnaeus, 1766 was characterized by the highest percentage of adenine in the third position (45.7\%) compared to other Arvicolinae. Ellobius lutescens

Thomas, 1897 demonstrated the highest percentage of cytosine in third position (37.1\%) among the 
277 Fig 1. Base composition in mitochondrial PCG of Arvicolinae. The frequency of the four bases (A,

$278 \mathrm{C}, \mathrm{G}$, and $\mathrm{T}$ ) at each codon position (first, second and third) in concatenated alignment was used as 12 279 variables for PCA. Tribes are indicated by colours.

\section{Substitution saturation analysis}

Substitution saturation decreases phylogenetic information contained in the sequences and plagues the phylogenetic analysis involving deep branches.

According to the analysis implemented in DAMBE software (S4 Table), the observed Iss saturation index was significantly $(\mathrm{P}<0.0001)$ lower than critical Iss.c value for both symmetrical and asymmetrical topology tests indicating the lack of saturation in the studied Arvicolinae dataset.

The results of saturation plots for separate genes show the same pattern of negligible saturation. As a result for all 13 PCGs, no significant saturation for the 1st and 2nd codon position, and they are all

291 taxonomic units, S4 Table).

\section{Time-calibrated mitochondrial genome phylogeny of Arvicolinae}

The maximum-likelihood (ML) and Bayesian inference (BI) trees reconstructed using complete and RY-coded alignments of PCGs had similar topology (Fig 2). Overall, ML analysis demonstrated 
and BI, with Bayesian probabilities BP $>0.95$ and ML bootstrap support BS $>95$ (Fig 2, nodes with a black dot).

Fig 2. Time-calibrated mitochondrial phylogeny of Arvicolinae. Node labels display the following

supports: BI complete / BI RY-coded 3rd codon position / ML complete / ML RY-coded 3rd codon position. Black circles show nodes with 0.95-1.0 BI and 95-100 ML support. All letters at nodes correspond to fossil constraints in S2 Table. Traditional tribal designations are also given above the branches and corresponding branches distinguished by different colors.

The monophyly of subfamily Arvicolinae was strongly supported by BI and ML analyses.

However, several nodes, predominantly the internal nodes representing deeper phylogenies, which were highly supported by Bayesian analysis, did not receive high BS values. The divergence time between Arvicolinae and Cricetinae was estimated as Late Miocene, ca. 11.31 / 10.7 Ma, based on the complete and RY-coded alignments respectively (Table 1).

Table 1. Divergence time estimates for the major lineages within the subfamily Arvicolinae.

\begin{tabular}{|l|l|l|}
\hline TMRCA & Complete & RY-masked \\
\hline Arvicolinae + Cricetinae & $\mathbf{1 1 . 3 1}(9.48-13.3)$ & $\mathbf{1 0 . 7}(8.42-13.31)$ \\
\hline Arvicolinae & $\mathbf{7 . 3 6}(7.04-7.78)$ & $\mathbf{7 . 3 3}(7.05-7.73)$ \\
\hline Lemmini & $\mathbf{4 . 8 1}(3.68-5.97)$ & $\mathbf{4 . 3 7}(3.31-5.71)$ \\
\hline Dicrostonychini + Ondatrini & $\mathbf{5 . 8 5}(5.15-6.56)$ & $\mathbf{5 . 5 4}(4.41-6.59)$ \\
\hline Dicrostonychini & $\mathbf{4 . 8 9}(4.08-5.7)$ & $\mathbf{4 . 4 9}(3.23-5.86)$ \\
\hline Clethrionomyini & $\mathbf{4 . 0 2}(3.33-4.72)$ & $\mathbf{4 . 4 6}(3.35-5.64)$ \\
\hline
\end{tabular}




\begin{tabular}{|c|c|c|}
\hline (Ellobiusini + Dinaromys $) /($ Arvicolini + Lagurini $)$ & $6.2(5.65-6.76)$ & $6.11(5.17-6.92)$ \\
\hline Ellobiusini & $4.97(4.21-5.69)$ & $4.58(3.42-5.68)$ \\
\hline Lagurini & $3.1(2.59-3.75)$ & $\mathbf{3 . 0 5}(2.56-3.75)$ \\
\hline Hyperacrius / Arvicolini & $5.76(5.2-6.34)$ & $5.79(4.88-6.63)$ \\
\hline Arvicolini s.str.* & $4.9(4.33-5.47)$ & $\mathbf{5 . 0 2}(4.12-5.89)$ \\
\hline Chionomys + Lemmiscus & $4.04(3.3-4.74)$ & $4.28(3.11-5.4)$ \\
\hline Chionomys & $3.29(2.5-4.04)$ & $3.45(2.13-4.67)$ \\
\hline Proedromys / & $4.32(3.81-4.86)$ & $4.52(3.69-5.33)$ \\
\hline $\begin{array}{l}\text { Microtus** } \quad \text { (Microtus, Sumeriomys } \\
\text { Blanfordimys, Agricola, Iberomys) }\end{array}$ & $3.8(3.31-4.3)$ & $3.87(3.07-4.63)$ \\
\hline Mynomes & $3.41(2.89-3.91)$ & $3.32(2.48-4.11)$ \\
\hline Microtus + Terricola & $2.96(2.46-3.5)$ & $3.18(2.35-3.95)$ \\
\hline Microtus & $1.87(1.43-2.33)$ & $2.06(1.31-2.8)$ \\
\hline Terricola & $1.38(0.89-1.93)$ & $1.46(0.7-2.32)$ \\
\hline Iberomys $+($ Agricola + Blanfordimys $)$ & $3.18(2.66-3.71)$ & $3.11(2.23-3.99)$ \\
\hline Agricola + Blanfordimys & $2.82(2.26-3.35)$ & $2.64(1.69-3.54)$ \\
\hline Neodon $+($ Alexandromys + Lasiopodomys $)$ & $3.92(3.4-4.4)$ & $4.12(3.31-4.9)$ \\
\hline Neodon & $3.16(2.58-3.76)$ & $3.3(2.43-4.23)$ \\
\hline Alexandromys + Lasiopodomys & $3.6(3.12-4.09)$ & $3.65(2.86-4.44)$ \\
\hline Lasiopodomys & $\mathbf{3 . 0 9}(2.59-3.56)$ & $\mathbf{3 . 0 7}(2.27-3.85)$ \\
\hline Alexandromys & $2.16(1.55-2.81)$ & $2.2(1.27-3.22)$ \\
\hline
\end{tabular}

Mean node ages marked in bold and 95\% highest posterior density intervals (in brackets) in million years

314 ago (Ma) estimated with two PCG datasets - complete and with RY-masked 3rd codon position.

* excluding Arvicola and Hyperacrius

** sensu Pardinas et al., 2017. 
The earliest radiation of the proper arvicolines (tribes Lemmini, Prometheomyini, Ondatrini and

319 Dicrostonychini) dates back to the Late Miocene with mean at 7.36 / 7.33 Ma. Despite the high node

320 support for the nodes marking tribes Lemmini and Dicrostonychini, the basal part of the phylogenetic

321 tree remains unresolved and represents a polytomy with several nodes not receiving significant BI and

ML support. Analysis based on the PCG dataset where the third codon position was not masked with

RY-coding, indicated significantly high Bayesian support for node C, combining Ondatrini and

Dicrostonychini (Fig 2). The time to MRCA of node $\mathrm{C}$ is about 5.85 / 5.54 Ma and the MRCA of proper

Dicrostonychini at 4.89 / 4.49 Ma.

The tribe Clethrionomyini representing second radiation of Arvicolinae received high BI and

ML support, and nodes within the clade were also highly supported. The MRCA for Clethrionomyini dates back to 4.02 / 4.46 Ma.

The cluster containing tribes Ellobiusini, Lagurini, Arvicolini and genera Dinaromys, Arvicola

Lacepede, 1799 and Hyperacrius Miller, 1896, i.e. the third radiation of Arvicolinae, was robustly supported by BI using both alignments and received reliable support by ML only with RY-masked alignment (Fig 2). Within this cluster, nodes marking tribes were highly supported by BI and ML. At the level of terminal branches within this cluster Dinaromys bogdanovi, Hyperacrius fertilis and Arvicola amphibius were the only to lack a certain phylogenetic position. D. bogdanovi grouped with Ellobiusini showing high BI support and no ML support. The water vole, Arvicola amphibius, clustered with Lagurini (high BP and no BS support) thus being paraphyletic to Arvicolini. The sagebrush vole Lemmiscus curtatus was sister to snow voles, Chionomys gud and C. nivalis Martins, 1842 with a robust support obtained in all analyses. The cluster of Chionomys Miller, 1908 and Lemmiscus was the earliest 
sensu stricto (excluding Arvicola) was fully resolved: both node H marking the whole tribe and all nodes

within the tribe received robust support in $\mathrm{ML}$ and BI analyses.

The estimated time of the largest radiation event within the subfamily and TMRCA for the

trichotomy Arvicolini - Ellobiusini - Lagurini dates back to 6.2 / 6.11 Ma. All following divergence

events within this radiation according to the obtained estimates took place very close to each other, the

95\% HPD of the diverging branches leading to MRCA of existing tribes are highly overlapping. Thus

the date estimate to the MRCA of Ellobiusini was 4.97 / 4.58 Ma. The MRCA of the Lagurini tribe is

around $3 \mathrm{Ma}$ (Fig 2, Table 1). The estimate for the earliest split within the Arvicolini tribe radiation (not

including Arvicola and Hyperacrius) with all recent genera is about 4.9/5.02 Ma, that coincides with

the onset of Pliocene period, whereas the major part of recent genera, excluding early derivating Chionomys, Lemmiscus and Proedromys Thomas, 1911, according to obtained estimates appear either

351 in the Middle Pliocene or close to the boundary of Late Pliocene-Early Pleistocene (Fig 2, Table 1).

\section{Gene trees}

The topology of the Arvicolinae phylogeny varied between the 13 PCG trees (S1 File). While tribe level nodes received good support at most of the trees, the phylogenetic relationships between the taxa remained unresolved. The ATP8-and COX2-based trees lacked resolution at both deep and shallow nodes, and therefore, these trees resulted in a complete polytomy. The only node at the ATP8-based tree that retained its integrity with high support was the tribe Clethrionomyini. Noteworthy that this Clethrionomyini node had high support and was consistent at the majority of the gene trees, except for the ND3. The node containing the taxa of the Arvicolini tribe (excluding Arvicola amphibius) received high support on the COX1, ATP6, ND3, ND5, ND6, ND1 and CYTB gene trees. The ND4 gene tree yielded in a highly supported node grouping the semiaquatic species - Ondatra zibethicus and Arvicola 
amphibius, the result was not supported by any other gene tree and mitogenome BI and ML phylogenetic

reconstructions (Fig 2). Positions of these two species, as well as Dinaromys bogdanovi were very

unstable across the individual gene trees.

\section{5}

\section{Discussion}

These taxa often occupied different positions and clustered with other species randomly. Remarkable that even in the case when tribal support and content was consistent across various trees and with the mitogenome tree, the interrelationships between tribes at the individual gene trees were unresolved. The lack of resolution especially at the deep nodes may be related to high saturation that is demonstrated with some genes, particularly $A T P 6, A T P 8, N D 1, N D 2, N D 3, N D 5$ and $N D 4$ (maximum saturation), since phylogenetic signal disappears when divergence is over $10 \%$.

Our phylogenetic reconstruction of the subfamily Arvicolinae is based on a PCG dataset of mitochondrial genome sequences of 58 species of voles and lemmings with the outgroup of six Cricetidae species. The dataset included 30 original sequences, and for 10 genera the mitogenomic sequencing was implemented for the first time. To date, this is the most comprehensive dataset aimed at the revision of the Arvicolinae phylogeny considering almost all recent genera represented by nominal species. While the monophyletic origin of Arvicolinae has always been considered indisputable, previous attempts to resolve phylogenetic relationships within the subfamily using either morphological analysis or combinations of mitochondrial and nuclear markers yielded in several hard polytomies [13] or conflicting topologies $[3,5-7,9,12,18,73,74]$. The more taxa and more markers were considered in the analysis, the better resolution for the nodes marking major tribes within Arvicolinae has been obtained $[7,17,18]$. However, the diversification events within major radiation waves remained unresolved. The 
phylogenetic position of the genera Prometheomys Satunin, 1901, Arvicola, Ondatra Link, 1795 and

Dinaromys in reconstructions performed with mitochondrial and nuclear markers was controversial

$[3,5,7,18]$ and genera Hyperacrius and Lemmiscus received little attention, their phylogenetic position was arguable.

Mismatches between the Bayesian and Maximum Likelihood support for the tribes and three waves of radiation within Arvicolini

The topology of the mitochondrial genome tree of Arvicolinae obtained in this study, in general, was in good agreement with previous large-scale phylogenetic reconstructions of the group based on mitochondrial and nuclear genes $[7,17,18,73,74]$. Using the concatenated alignment of 13 PCG, the present reconstruction resulted in high support for the nodes marking tribes in both Bayesian and Maximum Likelihood analyses. While Bayesian analysis also provided high BP support for the basal nodes, ML approach failed to recover relationships and order of divergence between the basal branches. Previously, these deep divergences were identified as three waves of rapid radiations [7].

The first radiation within the subfamily is represented by four tribes - Lemmini, Prometheomyini, Dicrostonychini (including Phenacomys Merriam, 1889) and Ondatrini. The order of divergence between these ancient tribes remains unresolved using mitochondrial genome data. The second radiation is represented exclusively by the large monophyletic tribe Clethrionomyini (Fig 2). These are predominantly forest-dwelling taxa originated in Eurasia with only a few species penetrating North America during the Pleistocene. According to our data, the monophyly of Clethrionomyini was supported in analyses of either concatenated alignment or individual mitochondrial genes except for the 405 short ND4L (S1 File). With all the nodes receiving high BP and ML support, the internal topology of 
406 branches within Clethrionomyini obtained in this study was similar to previous reconstructions of this

407 tribe based on one mitochondrial and three nuclear loci [11].

The third radiation comprises three tribes Arvicolini, Ellobiusini and Lagurini. While these tribes,

409 as well as most genera within the tribes, received strong support, and our reconstruction demonstrates

410 that all the taxa of the third radiation share the same putative common ancestor, their interrelationships

411 within this large clade also were not recovered, actually representing polytomy. According to our data,

412 the genera Dinaromys, Hyperacrius and Lemmiscus whose assignment to certain tribes has previously

413 been doubtful (Fig 2) also belong to the third radiation. Their taxonomic position, as well as the position

414 of the genus Arvicola that suddenly appeared to be paraphyletic to other Arvicolini, are discussed below. 
 \\ Phylogenetic relationships of the genus level taxa. Monotypic and low-}

\section{7 diverse genera of uncertain position}

The subfamily Arvicolinae includes several seriously understudied genera of unclear taxonomic position. For these genera, molecular data include either only mitochondrial CYTB sequences $[5,13-15]$ or several additional mitochondrial and nuclear markers $[3,7,9-11,18]$. These genera are often the orphan genera, i.e. being represented by a single extant species. Considering such taxa is of remarkable importance for the reconstruction of high-level phylogenies, but their position on a tree can often be contradictory due to long-branch attraction $[75,76]$. While the resolving power of the phylogenetic reconstruction increases with the number of genes in analysis, several studies of rapid radiations based on organellar genomes pointed out the effect of long branch attraction $[20,77,78]$ and references therein.

Our study, among other, considers five genera of the unclear position either within the first

(Prometheomys and Ondatra) or third (Dinaromys, Hyperacrius and Lemmiscus) radiation waves.

The Balkan vole, Dinaromys bogdanovi is endemic to Balkan Peninsula was attributed to either Ondatrini [79] or Prometheomyini [80], but conventionally to Clethrionomyini [39,81,82].

Morphologically Dinaromys is mostly close to the extinct Pliocene genus Pliomys Méhely, 1914 [39,83-

85], which distinguishes it from the rest of extant vole taxa. The genus Pliomys, in turn, has generally

been considered the ancestral form for the whole Clethrionomyini tribe. That was the main reason [39] to distinguish a separate subtribe Pliomyi within the latter consisting of the two genera - extant Dinaromys and extinct Pliomys. Until recently, CYTB was the only studied locus for Dinaromys, and it was placed as sister to Prometheomys, another monotypic genus, and both were close to Ellobiusini Arvicolini - Lagurini group [5]. This grouping was strongly rejected by the following attempts to build molecular phylogeny of Arvicolinae showing the position of Prometheomys as the earliest derivative 
Arvicola, i.e. the third radiation $[9,17,18]$. According to mitochondrial genome phylogeny (Fig 2),

Dinaromys does not have putative MRCA with monophyletic Clethrionomyini tribe and most likely

belongs to the third radiation, yet the certain position of this genus within this large group remains

unclear.

The analysis of partial mitochondrial CYTB sequence [11] demonstrated that genus Hyperacrius

does not seem to belong to the Clethrionomyini tribe. By analysing the set of mitogenomes of

Clethrionomyini and Arvicolini it was recently suggested that Hyperacrius has the basal position within

the tribe Arvicolini [50]. Here, using the broader taxonomic sampling, we confirm these previous

findings showing that Hyperacrius predates the diversification of all main genera of Arvicolini.

Reconstructions performed using the individual mitochondrial genes often placed genus Ondatra

as sister to Arvicola [5,13] or Clethrionomyini tribe [73] with low support. In all studies involving

varying sets of nuclear genes Ondatra was among early diverging lineages [7] and sister to Neofiber

True, 1884 if it was included in the analysis $[18,73]$. Such position better corresponds to conventional taxonomy and paleontological data. Our results placed Ondatra sister to the Dicrostonychini tribe, hence

with low support (except BI with transitions in the 3rd position included). Similar topology was observed by Lv et al. [17].

Lemmiscus curtatus - the sagebrush vole - is the only extant representative of the genus, it inhabits

semi-arid prairies on the western coast of North America. For a long time, Lemmiscus was considered as

closely related to the steppe voles Lagurini of the Old World and even as a subgenus within Lagurus

Gloger, 1841 [39,86-88]. The close affinity between Lemmiscus and the Palearctic Lagurini was then

seriously criticized from the paleontological perspective. Morphological similarities among the two

groups were interpreted as a result of the parallel evolution at open, steppe-like landscapes, and

Lemmiscus was proposed to be close to the tribe Arvicolini, particularly the genus Microtus Schrank, 
1798 [89]. These data corroborated the previous grouping of Microtus and Lemmiscus in phylogenetic

reconstruction based on restriction fragment LINE-1 [90], yet their taxonomic sampling did not include

Lagurini and most genera of the Arvicolini tribe. In a recent reconstruction using mitochondrial $C Y T B$

and the only nuclear gene Lemmiscus clustered with Arvicola amphibius, yet with no support [18].

Using mitochondrial genomes to reconstruct Arvicolinae phylogeny, we sensationally show that

Lemmiscus appears to be sister to the snow voles genus Chionomys. This clustering was obtained in all

variants of the analysis, and node support values were significant. The snow voles unite three species

occurring only in the Old World, particularly mountain systems of Southwestern, Central and

Southeastern Europe and Southwestern Asia. Snow voles inhabit rocky patches of a subalpine and alpine

belt from 500 up to $3500 \mathrm{~m}$ above the sea level $[39,91]$. Reliable pre-Pleistocene fossil remains of

Chionomys are unknown, and the origin of the genus was previously attributed to the mid-Pleistocene

[92]. Our data strongly contradicts this conventional view, and both Lemmiscus and Chionomys probably

are more ancient taxa. Also, Lemmiscus and Chionomys occur at different continents and occupy contrasting ecological niches; they are also very dissimilar morphologically. These findings, broadly discussed below, are important for the understanding of the migration events of Arvicolinae from Eurasia to North America.

\section{Phylogenetic relationships within the tribe Arvicolini sensu stricto}

By using the mitochondrial genome data, we obtained good support for the nodes within the tribe Arvicolini except for the Arvicola amphibius that clustered with Lagurini (Fig 2). The unclear position of A. amphibius can be a consequence of the long-branch attraction effect, and further studies should consider including sequences of the e.g. southern water wole, A. sapidus Miller, 1908 and nuclear 
hereafter called as Arvicolini sensu stricto marking the genus and subgenus level taxa, were recovered

485

as monophyletic and clearly resolved.

The phylogenetic pattern indicates two major migration waves of voles to the Nearctic. The earliest derivative from the MRCA is a branch leading to Chionomys - Lemmiscus node and this gives clear indication on the first dispersal of common ancestors of the group from Palearctic to Nearctic. The only recent descendant of this lineage in North America is Lemmiscus.

The next split of ancestral lineage evidently took place in Asia and is represented by poorly diversified genus Proedromys and highly diversified cluster, uniting all the rest recent vole genera. This latter cluster further splits into highly supported clade of Asian voles showing sister relationships of genus Neodon Horsfield, 1841 and genera Alexandromys Ognev, 1914 and Lasiopodomys Lataste, 1887 and a cluster uniting two sister clades: Nearctic voles with following fast radiation resulting in nearly 20 recent species (here named Mynomes Rafinesque, 1817 after the earliest name of the generic group level), and a clade that further splits into Western Palearctic (Microtus s.str., Terricola Fatio, 1867 and Sumeriomys Argyropulo, 1933) and one containing taxa distributed in Central Asia (Blanfordimys Argyropulo, 1933), Westernmost Europe (Iberomys Chaline, 1972) and wide-ranged Agricola Blasius, 1857 (from Western Europe to Siberia). It is important to note that trees uniting Nearctic "Microtus" species in one cluster were obtained in various studies $[12,15,17,18]$, but for the first time this cluster receives robust support, justifying the genus level status under the name Mynomes.

Another significant finding is the more clear assignment of Iberomys cabrerae and Agricola agrestis, both species conventionally assigned to Microtus [1], but whose position at the molecular trees within the Arvicolini tribe was always uncertain. The tendency for clusterization of A. agrestis and Blanfordimys, though without support was shown earlier $[9,12,15,17,18]$. In the paper where both $I$. cabrerae and A. agrestis were analysed in a comprehensive dataset with CYTB [15] these species 
appeared in different clusters: A. agrestis with Blanfordimys, while I. cabrerae within the cluster of

508 Nearctic voles, however later on [10] in a detailed study of Asian voles came up with analogous to 509 reported here clustering of I. cabrerae and A. agrestis with Blanfordimys. An important contribution was 510 recently made by Barbosa et al. [33] who used a genomic approach for resolving phylogeny of speciose 511 Microtus voles. According to their results both species appear to be monophyletic, however this study 512 was based only on eight species and lacked most of the genera of the group. According to our results the 513 cluster showing close relationships of these species with Blanfordimys is highly supported.

\section{Molecular estimates of Divergence time of the major Arvicolinae lineages}

\section{6 in the context of fossil record}

\section{Dating the origin of Arvicolinae}

Our data estimated the time of radiation from the MRCA of the all Arvicolinae as ca. $7.3 \mathrm{Ma}$

519 (Table 1), i.e. the Late Miocene and divergence time of Cricetinae and Arvicolinae from common ancestors around $11 \mathrm{Ma}$. These dating estimates correspond with fossil records [93] and molecular dating 521 obtained by previous studies [18]. Between the 11.1 and $7.75 \mathrm{Ma}$ (from Early Valesian to Late Turolian) in Eurasia appear many taxa, conventionally referred as microtoid cricetids. These forms were

523 characterised by the arvicoline-like prismatic dental pattern with variously pronounced hypsodonty [93$52496]$ and are generally considered as the ancestors for arvicolids [39,93-95,97]. The first fossil forms attributed to Arvicolinae (Pannonicola sp.) dated as ca. 7.3 Ma are known first from Middle Turolian, 


\section{Ancient radiation of Arvicolinae and the first migration event from Palearctic to}

528

Nearctic

From the mitochondrial genome data, the date for the MRCA of Lemmini was estimated as 4.814.37 Ma. This molecular dating consider ancestors of Lemmini almost a million years older than the fossil remains reliably attributed to Lemmini in Europe [100,101] and Asia [102] dated as the Early Villaniyan (Mammal Neogene zone MN16, 3.2 Ma), while North American fossils of Lemmini were dated at ca. 3.9 Ma or Late Blancan according to Ruez \& Gensler [103].

However, these lemming fossils are characterized by very advanced unrooted teeth and masticatory patterns, close to the recent forms of lemmings. Among the potential ancestors here can be mentioned Tobenia kretzoi Fejfar, Repenning, 1998, a species with rooted molars known from the early Pliocene of Wolfersheim, Germany [104]. This finding refers to MN15 that is ca. 4 Ma, similar to our molecular dating.

Divergence between Dicrostonychini and Ondatrini took place ca. 6 Ma according to our data, indicating that the ancestors of this group were very closely related to the first arvicolines. Feifar et al. [93] pointed that the molar pattern of Pannonicola Kretzoi, 1965, the oldest known fossil Arvicolinae, show similarity with Dolomys Nehring, 1898 the putative ancestor of Ondatrini, and possibly Dicrostonychini, indicating their closer relationships. Our data corroborate this grouping and provide additional evidence for the time estimate for the first dispersal of Arvicolinae from Palearctic to the Nearctic.

\section{Radiations of Arvicolinae in Late Miocene and Pliocene}

The molecular estimate of the two major radiation waves of Arvicolinae, leading to the Clethrionomyini, Arvicolini, Ellobiusini and Lagurini, dates back to 6 Ma, Late Miocene, MN 13 (Late 
Turolian). These findings correspond to paleontological data and confirm the estimates received

previously in the study based on nuclear genes [7]. Chronologically, this was the period of simultaneous appearance of Promimomys Kretzoi, 1955 in Eastern Europe [93] and Western Asia [105]. This form is considered ancestral to numerous species emerged in the Early Pliocene and conventionally assigned to highly mixed and species-rich genus Mimomys Forsyth-Major, 1902. According to the generally

accepted view, different forms of this complex "Mimomys" group represented the starting point for all

subsequent lineages of Arvicolines. The concept of common ancestry for these forms within this

geological period does not contradict the data obtained in the present study and hypothesis proposed by

paleontologists [93]. The radiation of common ancestors for all Clethrionomyini species starts later, since

Late Ruscinian (MN 15), around 4 Ma.

\section{The origin of the tribe Arvicolini sensu stricto: second trans-Beringian dispersal}

The molecular estimate for the MRCA of node H, Arvicolini s.str. (Fig 2) is ca. 5 Ma.

Considering that most primitive forms of the genus Mimomys are among the MRCA candidates for all main genera within the tribe Arvicolini s.str, the obtained time estimate i.e. the very beginning of the Pliocene is also consistent with the fossil record.

One of the earliest records of Mimomys in North America was dated as 4.75 Ma [106], while fossil remains from Asia are slightly older [107]. This is the time of the second dispersal of arvicolids from Asia to the Nearctic. The only recent descendant of these immigrants in North America is Lemmiscus curtatus. According to our data, the starting point of evolutionary history for this lineage is around $4 \mathrm{Ma}$. The earliest remains assigned to the genus are known from the end of Early Pleistocene from the SAM Cave in New Mexico [108] in the sediments according to paleomagnetic and faunistic data that may be dated as 1.8 Ma. Repenning [108] deduced Lemmiscus from primitive Allophaiomys 
sites dated between 2.2 and 1.6 Ma in both the Palearctic and Nearctic. Yet, Allophaiomys is a rather

573 collective taxon presumably accepted as ancestral to most Microtus species and associated genera.

574 Tesakov and Kolfschoten [89] suggested the hypothesis of a Mimomys-Lemmiscus phyletic lineage.

575 However, their hypothesis also presumes that ancestral Mimomys (Cromeromys Zazhigin, 1980), a form

576 having rooted molars and inhabiting vast areas from Western Europe to Beringia dispersed southwards

577 across North America in the late Early Pleistocene and evolved there into rootless Lemmiscus. Thus, our 578 dating conflicts with both views and supports the idea of dispersal and further evolution from "Mimomys" 579 stage $[89,108]$ in the middle of the Pliocene, ca. 4 Ma. The fossil remains of Chionomys are known only 580 from the Pleistocene sediments [92]. According to our dating based on mtDNA, the diversification of 581 ancestral lineage may have started in Western Palearctic as early as in the Middle Pliocene.

Diversification within Arvicolini sensu stricto: Late Pliocene exchange between

\section{Palearctic and Nearctic faunas}

The other genera within Arvicolini were monophyletic according to Bayesian and ML analyses with high node support. According to conventional view, this group originated from Allophaiomys [39,108], a highly complex taxon common in the Early Pleistocene (ca. 2 Ma) faunas of the Nearctic and Palearctic. Our results on divergence dating raise another hypothesis on the starting point for the group is taking place at the level of "Mimomys" stage, i.e. in the Late Pliocene. The genus Proedromys is the first derivative from this common stem, most likely in the Middle Pliocene (approx. $4 \mathrm{Ma}$ ). The standalone position of this genus among other genera of Arvicolini, that plausibly derived from 
A further split within Arvicolini took place in the late Pliocene and resulted in the entirely Asian

594 lineage which currently represented by genera Neodon, Alexandromys and Lasiopodomys. The other, 595 sister lineage emerged in the Late Pliocene, around 3.8-4 Ma, also from the pre-Allophaiomys stage and 596 diverged into two branches. Ancestors of the first branch (Mynomes) penetrated the Nearctic during the and watershed between the Yenisey and Lena Rivers [1,39]. Recent studies showed that Agricola is

614 represented by three highly divergent lineages, possibly a species level taxa [111]. Three species of 615 Blanfordimys occur in high mountain forests and steppes of Central Asia and are characterized by a very 
616 primitive molar pattern, similar to Allophaiomys. The idea that Agricola and Iberomys represent relicts

617 of a very early colonization of Arvicolini to Western Europe was earlier suggested by Martinkova and

618 Moravec [16] and well agrees with the given data.

The second lineage of Palearctic branch has evolved in Western Palearctic and in the modern

fauna is represented by species-rich genus Microtus (with subgenera Microtus s.str and Sumeriomys) and

Terricola (around 14 species, mainly found in South and Southwestern Europe). The divergence between

these lineages corresponds to the Late Pliocene, however the speciation events coincided with Early

Pleistocene for genus Terricola and early Middle Pleistocene for subgenera Sumeriomys and Microtus.

624 The latter dating matches with known fossil records [85,112].

Summing up the comparison between the molecular estimates of divergence times reported here

and known paleontological data, it is curious to note that while the dates for MRCA for most genera

within Arvicolini s.str. significantly older than was previously supposed [85,93,113], dating of speciation

events within the genera (Lasiopodomys, Alexandromys, Terricola) are consistent with fossil record $[85,106,108,112-114]$ and other.

\section{0}

\section{Systematic remarks}

While systematic relationships of higher taxa within Arvicolinae undoubtedly require further studies involving genomic approaches, some amendments to the current taxonomic system could be made already at this step of the research. Our study provided significant input for the potential review of taxonomic structure and composition of the tribe Arvicolini (S2 File). Our data shows that the position of the genus Arvicola is still unresolved. On the contrary, genera Lemmiscus and Hyperacrius certainly should be considered as members of the tribe Arvicolini. The further grouping of species into genera and 
638 the composition of the genus Microtus. The current system [1] where Blanfordimys, Neodon and

639 Lasiopodomys have generic status, while Alexandromys, Stenocranius and Terricola are referred as

640 subgenera within the genus Microtus is strongly outdated and contradicts the data of recent phylogenetic

641 studies. The last checklist [2] partly modified this scheme and following Abramson and Lissovsky [40]

642 elevated Alexandromys to full genus and Stenocranius considered as subgenus of Lasiopodomys, and

643 Neodon as a genus. However, despite the accumulated evidence from several previous papers $[9,16,115]$,

644 in this reference book without substantiation the status of Blanfordimys was downgraded [116] while

645 three well differentiated lineages (Blanfordimys, all Nearctic microtines, Terricola, Microtus and

646 Sumeriomys) were illogically united in one genus Microtus. These well-differentiated lineages together

647 form the sister branch to one with similar branching pattern and recognized three genera: Alexandromys,

648 Lasiopodomys and Neodon. It is widely known, that the better is the phylogenetic resolution of any

species-rich group the more complicated it matches the conventional hierarchical categories of Linnean

650 system. Trying to retain as much stability of nomenclature retaining the already commonly used names

651 that correspond to certain lineages from one hand and to reflect robust phylogenetic nodes in a formal

652 classification from the other, here we suggest the following system of generic group taxa within the tribe

653 Arvicolini sensu stricto.

\section{Conclusions}

Our phylogenetic analysis based on a complete mitochondrial genomes confirmed the monophyly

657 of the subfamily, monophyly of the most tribes originated during the three subsequent radiation events.

658 While order of divergence between ancient genera belonging to the first radiation were not uniformly 
resolved several previously reported polytomies and also revealed unexpected relationships between

662

663

664

665

666

667

668

669

\section{Acknowledgments}

We are grateful to colleagues who shared the material for the study - Abramov A.V., Golenishchev F.N., Stekolnikov A.A., Bannikova A.A., Chabovskiy A.V., Kowalskaya Yu.M., Smorkatcheva A.V., Dokuchaev N.E., Bogdanov A.S., Grafodatsky A.S., Buzan E. We would like to thank Margarita Ezhova and Maria Logacheva from the Genomics Core Facility of Skolkovo Institute 
683 of Science and Technology for NGS library preparation. Special thanks to Dr. Rudolf Haslauer,

684 Zoological Society for the Conservation of Species and Populations (ZGAP), Poernbach, Bavaria, for 685 fruitful discussion of taxonomy issues.

\section{References}

689 1. Musser GG, Carleton MD. Superfamily Muroidea. Mammal species of the world: a taxonomic 690 and geographic reference. JHU Press; 2005. pp. 894-1531.

691 2. Pardiñas UFJ, Myers P, León-Paniagua L, Ordóñez Garza N, Cook JA, Kryštufek B, et al. Family 692 Cricetidae (true hamsters, voles, lemmings and new world rats and mice). Handb Mamm World. 2017;7: 204-279.

694 3. Galewski T, Tilak M, Sanchez S, Chevret P, Paradis E, Douzery EJ. The evolutionary radiation 695 of Arvicolinae rodents (voles and lemmings): relative contribution of nuclear and mitochondrial DNA phylogenies. BMC Evol Biol. 2006;6: 80. doi:10.1186/1471-2148-6-80

697 4. Lebedev VS, Bannikova AA, Tesakov AS, Abramson NI. Molecular phylogeny of the genus Alticola (Cricetidae, Rodentia) as inferred from the sequence of the cytochrome b gene. Zool Scr. 2007;36: 547-563. doi:10.1111/j.1463-6409.2007.00300.x

5. Buzan EV, Krystufek B, Hänfling B, Hutchinson WF. Mitochondrial phylogeny of Arvicolinae using comprehensive taxonomic sampling yields new insights. Biol J Linn Soc. 2008;94: 825835. doi:10.1111/j.1095-8312.2008.01024.X 
703 6. Robovský J, ŘIčánková V, Zrzavý J. Phylogeny of Arvicolinae (Mammalia, Cricetidae): utility of morphological and molecular data sets in a recently radiating clade. Zool Scr. 2008;37: 571-590. doi:10.1111/j.1463-6409.2008.00342.x

\section{6}

7. Abramson NI, Lebedev VS, Tesakov AS, Bannikova AA. Supraspecies relationships in the subfamily Arvicolinae (Rodentia, Cricetidae): An unexpected result of nuclear gene analysis. Mol Biol. 2009;43: 834. doi:10.1134/S0026893309050148

8. Bannikova AA, Lebedev VS, Lissovsky AA, Matrosova V, Abramson NI, Obolenskaya EV, et al. Molecular phylogeny and evolution of the Asian lineage of vole genus Microtus (Rodentia: Arvicolinae) inferred from mitochondrial cytochrome b sequence. Biol J Linn Soc. 2010;99: 595613. doi:10.1111/j.1095-8312.2009.01378.x

9. Fabre P-H, Hautier L, Dimitrov D, P Douzery EJ. A glimpse on the pattern of rodent diversification: a phylogenetic approach. BMC Evol Biol. 2012;12: 88. doi:10.1186/1471-2148$12-88$

10. Liu SY, Sun ZY, Liu Y, Wang H, Guo P, Murphy RW. A new vole from Xizang, China and the molecular phylogeny of the genus Neodon (Cricetidae: Arvicolinae). Zootaxa. 2012;3235: 1-22. doi:10.11646/zootaxa.3235.1.1

11. Kohli BA, Speer KA, Kilpatrick CW, Batsaikhan N, Damdinbaza D, Cook JA. Multilocus systematics and non-punctuated evolution of Holarctic Myodini (Rodentia: Arvicolinae). Mol Phylogenet Evol. 2014;76: 18-29. doi:10.1016/j.ympev.2014.02.019

12. Pradhan N, Sharma AN, Sherchan AM, Chhetri S, Shrestha P, Kilpatrick CW. Further assessment of the Genus Neodon and the description of a new species from Nepal. PLOS ONE. 2019;14: e0219157. doi:10.1371/journal.pone.0219157 
725 13. Conroy CJ, Cook JA. MtDNA Evidence for Repeated Pulses of Speciation Within Arvicoline and Murid Rodents. J Mamm Evol. 1999;6: 221-245. doi:10.1023/A:1020561623890

14. Conroy CJ, Cook JA. Molecular Systematics of a Holarctic Rodent (Microtus: Muridae). J Mammal. 2000;81: 344-359. doi:10.1644/1545-1542(2000)081<0344:MSOAHR>2.0.CO;2

15. Jaarola M, Martínková N, Gündüz İ, Brunhoff C, Zima J, Nadachowski A, et al. Molecular phylogeny of the speciose vole genus Microtus (Arvicolinae, Rodentia) inferred from mitochondrial DNA sequences. Mol Phylogenet Evol. 2004;33: 647-663. doi:10.1016/j.ympev.2004.07.015

16. Martínková N, Moravec J. Multilocus phylogeny of arvicoline voles (Arvicolini, Rodentia) shows small tree terrace size. J Vertebr Biol. 2012;61: 254-267. doi:10.25225/fozo.v61.i3.a10.2012

17. Lv X, Xia L, Ge D, Wu Y, Yang Q. Climatic niche conservatism and ecological opportunity in the explosive radiation of arvicoline rodents (Arvicolinae, Cricetidae). Evolution. 2016;70: 10941104. doi:10.1111/evo.12919

18. Steppan SJ, Schenk JJ. Muroid rodent phylogenetics: 900-species tree reveals increasing diversification rates. PLOS ONE. 2017;12: e0183070. doi:10.1371/journal.pone.0183070

19. Vilstrup JT, Ho SY, Foote AD, Morin PA, Kreb D, Krützen M, et al. Mitogenomic phylogenetic analyses of the Delphinidae with an emphasis on the Globicephalinae. BMC Evol Biol. 2011;11: 65. doi:10.1186/1471-2148-11-65

20. Li T, Hua J, Wright AM, Cui Y, Xie Q, Bu W, et al. Long-branch attraction and the phylogeny of true water bugs (Hemiptera: Nepomorpha) as estimated from mitochondrial genomes. BMC Evol Biol. 2014;14: 99. doi:10.1186/1471-2148-14-99 
746 21. Lee Y, Kwak H, Shin J, Kim S-C, Kim T, Park J-K. A mitochondrial genome phylogeny of

Mytilidae (Bivalvia: Mytilida). Mol Phylogenet Evol. 2019;139: 106533.

doi:10.1016/j.ympev.2019.106533

749

750

751

752

753

754

755

756

757

758

759

760

761

762

763

764

765

766

767

22. Hassanin A, Bonillo C, Tshikung D, Shongo CP, Pourrut X, Kadjo B, et al. Phylogeny of African fruit bats (Chiroptera, Pteropodidae) based on complete mitochondrial genomes. J Zool Syst Evol Res. 2020;58: 1395-1410. doi:10.1111/jzs.12373

23. da Silva FS, Cruz ACR, de Almeida Medeiros DB, da Silva SP, Nunes MRT, Martins LC, et al. Mitochondrial genome sequencing and phylogeny of Haemagogus albomaculatus, Haemagogus leucocelaenus, Haemagogus spegazzinii, and Haemagogus tropicalis (Diptera: Culicidae). Sci Rep. 2020;10: 16948. doi:10.1038/s41598-020-73790-x

24. Kim HR, Park YC. The complete mitochondrial genome of the Korean red-backed vole, Myodes regulus (Rodentia, Murinae) from Korea. Mitochondrial DNA. 2012;23: 148-150. doi:10.3109/19401736.2012.660932

25. Yang C, Hao H, Liu S, Liu Y, Yue B, Zhang X. Complete mitochondrial genome of the Chinese oriental vole Eothenomys chinensis (Rodentia: Arvicolinae). Mitochondrial DNA. 2012;23: 131133. doi:10.3109/19401736.2012.660926

26. Bendová K, Marková S, Searle JB, Kotlík P. The complete mitochondrial genome of the bank vole Clethrionomys glareolus (Rodentia: Arvicolinae). Mitochondrial DNA Part A. 2016;27: 111112. doi:10.3109/19401736.2013.873927

27. Cao W, Xia Y, Dang X, Xu Q. The first complete mitochondrial genome of the Microtus ochrogaster. Mitochondrial DNA Part A. 2016;27: 3682-3683. doi:10.3109/19401736.2015.1079854 
28. Chen S, Chen G, Wei H, Wang Q. Complete mitochondrial genome of the Père David's Vole, Eothenomys melanogaster (Rodentia: Arvicolinae). Mitochondrial DNA Part DNA Mapp Seq Anal. 2016;27: 2496-2497. doi:10.3109/19401736.2015.1036246

29. Cong H, Kong L, Liu Z, Wu Y, Motokawa M, Harada M, et al. Complete mitochondrial genome of the mandarin vole Lasiopodomys mandarinus (Rodentia: Cricetidae). Mitochondrial DNA Part A. 2016;27: 760-761. doi:10.3109/19401736.2014.915528

30. Fedorov VB, Goropashnaya AV. Complete mitochondrial genome of the Eurasian collared lemming Dicrostonyx torquatus Pallas, 1779 (Rodentia: Arvicolinae). Mitochondrial DNA Part B. 2016;1: 824-825. doi:10.1080/23802359.2016.1247664

31. Fedorov VB, Goropashnaya AV. Complete mitochondrial genomes of the North American collared lemmings Dicrostonyx groenlandicus Traill, 1823 and Dicrostonyx hudsonius Pallas, 1778 (Rodentia: arvicolinae). Mitochondrial DNA Part B. 2016;1: 878-879. doi:10.1080/23802359.2016.1253041

32. Yu P, Kong L, Li Y, Cong H, Li Y. Analysis of complete mitochondrial genome and its application to phylogeny of Caryomys inez (Rodentia: Cricetidae: Arvicolinae). Mitochondrial DNA Part B. 2016;1: 343-344. doi:10.1080/23802359.2016.1172275

33. Barbosa S, Paupério J, Pavlova SV, Alves PC, Searle JB. The Microtus voles: Resolving the phylogeny of one of the most speciose mammalian genera using genomics. Mol Phylogenet Evol. 2018;125: 85-92. doi:10.1016/j.ympev.2018.03.017

34. Folkertsma R, Westbury MV, Eccard JA, Hofreiter M. The complete mitochondrial genome of the common vole, Microtus arvalis (Rodentia: Arvicolinae). Mitochondrial DNA Part B. 2018;3: 446-447. doi:10.1080/23802359.2018.1457994 
790 35. Jiang J-Q, Wu S-X, Chen J-J, Liu C-Z. Characterization of the complete mitochondrial genome of short-tailed field vole, Microtus agrestis. Mitochondrial DNA Part B. 2018;3: 845-846. doi:10.1080/23802359.2018.1467240

36. Zhao H, Qi X, Li C. Complete mitochondrial genome of the muskrat (Ondatra zibethicus) and its unique phylogenetic position estimated in Cricetidae. Mitochondrial DNA Part B. 2018;3: 296298. doi:10.1080/23802359.2017.1390402

37. Li J-Q, Li L, Fu B-Q, Yan H-B, Jia W-Z. Complete mitochondrial genomes confirm the generic placement of the plateau vole, Neodon fuscus. Biosci Rep. 2019;39. doi:10.1042/BSR20182349

38. Mu Y, Duan Y, Di Z, Wang Z, Wanlong Z. The complete mitochondrial genome of the Yunnan red-backed vole Eothenomys miletus (Rodentia: Cricetidae) and its phylogeny. Mitochondrial DNA Part B. 2019;4: 1424-1425. doi:10.1080/23802359.2019.1598801

39. Gromov IM, Polyakov IY. Voles (Microtinae). Brill; 1992.

40. Abramson NI, Lissovsky AA. Subfamily Arvicolinae. In: Pavlinov IY, Lissovsky AA, editors. The mammals of Russia: A taxonomic and geographic reference. KMK Scientific Press; 2012. pp. $127-141$.

41. Köchl S, Niederstätter H, Parson W. DNA Extraction and Quantitation of Forensic Samples Using the Phenol-Chloroform Method and Real-Time PCR. In: Carracedo A, editor. Forensic DNA Typing Protocols. Totowa, NJ: Humana Press; 2005. pp. 13-29. doi:10.1385/1-59259-867-6:013

42. Andrews S. FastQC: A Quality Control Tool for High Throughput Sequence Data. 2016. Available: http://www.bioinformatics.babraham.ac.uk/projects/fastqc/

43. Bolger AM, Lohse M, Usadel B. Trimmomatic: a flexible trimmer for Illumina sequence data. Bioinformatics. 2014;30: 2114-2120. doi:10.1093/bioinformatics/btu170 
44. Langmead B, Trapnell C, Pop M, Salzberg SL. Ultrafast and memory-efficient alignment of short

DNA sequences to the human genome. Genome Biol. 2009;10: R25. doi:10.1186/gb-2009-10-3-

45. Jónsson H, Ginolhac A, Schubert M, Johnson PLF, Orlando L. mapDamage2.0: fast approximate Bayesian estimates of ancient DNA damage parameters. Bioinformatics. 2013;29: 1682-1684. doi:10.1093/bioinformatics/btt193

46. Bankevich A, Nurk S, Antipov D, Gurevich AA, Dvorkin M, Kulikov AS, et al. SPAdes: A New

Genome Assembly Algorithm and Its Applications to Single-Cell Sequencing. J Comput Biol. 2012;19: 455-477. doi:10.1089/cmb.2012.0021

47. Bernt M, Donath A, Jühling F, Externbrink F, Florentz C, Fritzsch G, et al. MITOS: Improved de novo metazoan mitochondrial genome annotation. Mol Phylogenet Evol. 2013;69: 313-319. doi:10.1016/j.ympev.2012.08.023

48. Bondareva OV, Abramson NI. The complete mitochondrial genome of the common pine vole Terricola subterraneus (Arvicolinae, Rodentia). Mitochondrial DNA Part B. 2019;4: 3925-3926. doi:10.1080/23802359.2019.1687026

49. Bondareva OV, Mahmoudi A, Bodrov SY, Genelt-Yanovskiy EA, Petrova TV, Abramson NI. The complete mitochondrial genomes of three Ellobius mole vole species (Rodentia: Arvicolinae). Mitochondrial DNA Part B. 2020;5: 2485-2487. doi:10.1080/23802359.2020.1778567

50. Abramson NI, Golenishchev FN, Bodrov SY, Bondareva OV, Genelt-Yanovskiy EA, Petrova TV. Phylogenetic relationships and taxonomic position of genus Hyperacrius (Rodentia: Arvicolinae) from Kashmir based on evidences from analysis of mitochondrial genome and study of skull morphology. PeerJ. 2020;8: e10364. doi:10.7717/peerj.10364 
834 51. Li B, Wolsan M, Wu D, Zhang W, Xu Y, Zeng Z. Mitochondrial genomes reveal the pattern and

835 timing of marten (Martes), wolverine (Gulo), and fisher (Pekania) diversification. Mol Phylogenet Evol. 2014;80: 156-164. doi:10.1016/j.ympev.2014.08.002

52. Song N, Li X, Na R. Mitochondrial genomes of stick insects (Phasmatodea) and phylogenetic considerations. PLOS ONE. 2020;15: e0240186. doi:10.1371/journal.pone.0240186

53. Katoh K, Misawa K, Kuma K, Miyata T. MAFFT: a novel method for rapid multiple sequence alignment based on fast Fourier transform. Nucleic Acids Res. 2002;30: 3059-3066. doi:10.1093/nar/gkf436

54. Breinholt JW, Kawahara AY. Phylotranscriptomics: Saturated Third Codon Positions Radically Influence the Estimation of Trees Based on Next-Gen Data. Genome Biol Evol. 2013;5: 20822092. doi:10.1093/gbe/evt157

55. Arabi J, Cruaud C, Couloux A, Hassanin A. Studying sources of incongruence in arthropod molecular phylogenies: Sea spiders (Pycnogonida) as a case study. C R Biol. 2010;333: 438-453. doi:10.1016/j.crvi.2010.01.018

56. Lobry JR. Properties of a general model of DNA evolution under no-strand-bias conditions. J Mol Evol. 1995;40: 326-330. doi:10.1007/BF00163237

57. Kumar S, Stecher G, Li M, Knyaz C, Tamura K. MEGA X: Molecular Evolutionary Genetics Analysis across Computing Platforms. Mol Biol Evol. 2018;35: 1547-1549. doi:10.1093/molbev/msy096

58. Hammer O, Harper D, Ryan P. PAST: Paleontological Statistics Software Package for Education and Data Analysis. Palaeontol Electron. 2001;4: 1-9.

59. Xia X, Xie Z, Salemi M, Chen L, Wang Y. An index of substitution saturation and its application. Mol Phylogenet Evol. 2003;26: 1-7. doi:10.1016/S1055-7903(02)00326-3 
60. Xia X. DAMBE7: New and Improved Tools for Data Analysis in Molecular Biology and Evolution. Mol Biol Evol. 2018;35: 1550-1552. doi:10.1093/molbev/msy073

61. Xia X, Lemey P. Assessing substitution saturation with DAMBE. 2nd ed. In: Vandamme A-M,

Salemi M, Lemey P, editors. The Phylogenetic Handbook: A Practical Approach to Phylogenetic

62. Charif D, Lobry JR. SeqinR 1.0-2: A Contributed Package to the R Project for Statistical

Computing Devoted to Biological Sequences Retrieval and Analysis. In: Bastolla U, Porto M,

64. Lanfear R, Frandsen PB, Wright AM, Senfeld T, Calcott B. PartitionFinder 2: New Methods for Selecting Partitioned Models of Evolution for Molecular and Morphological Phylogenetic Analyses. Mol Biol Evol. 2017;34: 772-773. doi:10.1093/molbev/msw260

65. Trifinopoulos J, Nguyen L-T, von Haeseler A, Minh BQ. W-IQ-TREE: a fast online phylogenetic tool for maximum likelihood analysis. Nucleic Acids Res. 2016;44: W232-W235. doi:10.1093/nar/gkw256

66. Hoang DT, Chernomor O, von Haeseler A, Minh BQ, Vinh LS. UFBoot2: Improving the Ultrafast Bootstrap Approximation. Mol Biol Evol. 2018;35: 518-522. doi:10.1093/molbev/msx281 
878 67. Ronquist F, Teslenko M, van der Mark P, Ayres DL, Darling A, Höhna S, et al. MrBayes 3.2:

879

Efficient Bayesian Phylogenetic Inference and Model Choice Across a Large Model Space. Syst Biol. 2012;61: 539-542. doi:10.1093/sysbio/sys029

68. Rambaut A, Drummond AJ, Xie D, Baele G, Suchard MA. Posterior Summarization in Bayesian Phylogenetics Using Tracer 1.7. Syst Biol. 2018;67: 901-904. doi:10.1093/sysbio/syy032

69. Miller MA, Pfeiffer W, Schwartz T. Creating the CIPRES Science Gateway for inference of large phylogenetic trees. 2010 Gateway Computing Environments Workshop (GCE). 2010. pp. 1-8. doi:10.1109/GCE.2010.5676129

70. Bouckaert R, Vaughan TG, Barido-Sottani J, Duchêne S, Fourment M, Gavryushkina A, et al. BEAST 2.5: An advanced software platform for Bayesian evolutionary analysis. PLOS Comput Biol. 2019;15: e1006650. doi:10.1371/journal.pcbi.1006650

71. Darriba D, Taboada GL, Doallo R, Posada D. jModelTest 2: more models, new heuristics and parallel computing. Nat Methods. 2012;9: 772-772. doi:10.1038/nmeth.2109

72. Molto JE, Loreille O, Mallott EK, Malhi RS, Fast S, Daniels-Higginbotham J, et al. Complete Mitochondrial Genome Sequencing of a Burial from a Romano-Christian Cemetery in the Dakhleh Oasis, Egypt: Preliminary Indications. Genes. 2017;8: 262. doi:10.3390/genes8100262

73. Chen W-C, Hao H-B, Sun Z-Y, Liu Y, Liu S-Y, Yue B-S. Phylogenetic position of the genus Proedromys (Arvicolinae, Rodentia): Evidence from nuclear and mitochondrial DNA. Biochem Syst Ecol. 2012;42: 59-68. doi:10.1016/j.bse.2012.01.002

74. Schenk JJ, Rowe KC, Steppan SJ. Ecological Opportunity and Incumbency in the Diversification of Repeated Continental Colonizations by Muroid Rodents. Syst Biol. 2013;62: 837-864. doi:10.1093/sysbio/syt050 
900 75. Wiens JJ. Can Incomplete Taxa Rescue Phylogenetic Analyses from Long-Branch Attraction? $901 \quad$ Syst Biol. 2005;54: 731-742. doi:10.1080/10635150500234583

902 76. Brinkmann H, van der Giezen M, Zhou Y, de Raucourt GP, Philippe H. An Empirical Assessment of Long-Branch Attraction Artefacts in Deep Eukaryotic Phylogenomics. Syst Biol. 2005;54: 743-757. doi:10.1080/10635150500234609

77. Straub SCK, Moore MJ, Soltis PS, Soltis DE, Liston A, Livshultz T. Phylogenetic signal detection from an ancient rapid radiation: Effects of noise reduction, long-branch attraction, and model selection in crown clade Apocynaceae. Mol Phylogenet Evol. 2014;80: 169-185. doi:10.1016/j.ympev.2014.07.020

78. Zou H, Jakovlić I, Zhang D, Hua C-J, Chen R, Li W-X, et al. Architectural instability, inverted skews and mitochondrial phylogenomics of Isopoda: outgroup choice affects the long-branch attraction artefacts. R Soc Open Sci. 7: 191887. doi:10.1098/rsos.191887

79. Corbet G. B. The mammals of the palaearctic region. a taxonomic review. London and Ithaca (NY): British Museum (Natural History) and Cornell University Press; 1978.

80. Pavlinov IY. Systematics of Recent mammals. Moscow: Moscow University Press; 2003.

81. Hooper ET, Hart BS. A synopsis of Recent North American microtine rodents. Miscellaneous Publications of the Museum of Zoology, University of Michigan; 1962.

82. Mckenna MC, Bell SK. Review of Classification of Mammals above the Species Level. J Vertebr Paleontol. 1997;19: 191-195.

83. Kretzoi M. 1969. Skizze einer Arvicoliden-Phylogenie-Stand 1969. Vertebr Hung Musei Hist Hung. 1969;11: 155-193.

84. von Koenigswald W, KOENIGSWALD V. Schmelzstruktur und Morphologie in den Molaren der Arvicolidae (Rodentia). 1980. 
923 85. Chaline J, Brunet-Lecomte P, Montuire S, Viriot L, Courant F. Anatomy of the arvicoline radiation (Rodentia): palaeogeographical, palaeoecological history and evolutionary data. Annales Zoologici Fennici. JSTOR; 1999. pp. 239-267.

926

927

928

929

930

931

932

933

934

935

936

937

938

939

940

941

942

943

944

89. Tesakov AS, van Kolfschoten T. The Early Pleistocene Mimomys hordijki (Arvicolinae, Rodentia) from Europe and the origin of modern nearctic sagebrush voles (Lemmiscus). Palaeontol Electron. 2011;14: 1-11.

90. Modi WS. Phylogenetic history of LINE-1 among arvicolid rodents. Mol Biol Evol. 1996;13: 633-641. doi:10.1093/oxfordjournals.molbev.a025623

91. Barros P, Vale-Gonçalves HM, Paupério J, Cabral JA, Rosa G. Confirmation of European snow vole Chionomys nivalis (Mammalia: Rodentia: Cricetidae) occurrence in Portugal. Ital J Zool. 2016;83: 139-145. doi:10.1080/11250003.2015.1103320

92. Yannic G, Burri R, Malikov VG, Vogel P. Systematics of snow voles (Chionomys, Arvicolinae) revisited. Mol Phylogenet Evol. 2012;62: 806-815. doi:10.1016/j.ympev.2011.12.004

93. Fejfar O, Heinrich W-D, Kordos L, Maul L. Microtoid cricetids and the Early history of arvicolids (Mammalia, Rodentia). Palaeontol Electron. 2011;14.

94. Schaub S. Über einige Simplicidentaten ausChina und Mongolei. Abh Schweiz-Schen Paläontol Ges. 1934;54: 1-40.

95. Fejfar O. Microtoid Cricetids. The Miocene Land Mammals of Europe. Rössner GE, Heissig K, editors. München, Germany.: Verlag Dr. Friedrich Pfeil; 1999. 
96. Maridet O. An Early Miocene microtoid cricetid (Rodentia, Mammalia) from the Junggar Basin of Xinjiang, China. Acta Palaeontol Pol. 2014 [cited 17 Feb 2021]. doi:10.4202/app.2012.0007

97. Kretzoi M. Acta Geologica Hungarica. Dolomys Ondatra. 1955;3: 347-355.

949 98. Kretzoi M. Pannonicola brevidens n.g n.sp., ein echter Arvicolide aus dem ungarischen Unterpliozän. Vertebr Hung Musei Hist-Nat Hung. 1965;7: 131-139.

951 99. Zazhigin VS. Order Rodentia-rodents. In: Shanzer EV, editor. Stratigraphy of the USSR: The Quaternary system. Moscow: Nedra; 1982. pp. 294-305.

100. Kowalski K. Fossil lemmings (Mammalia, Rodentia) from the Pliocene and early Pleistocene of Poland. 1977;22: 297-317.

101. Sukhov VP. Remains of lemmings in the Pliocene deposits of Bashkiria. Proc Zool Inst. 1976;66: $117-121$.

102. Devyatkin EV, Zazhigin VS. Eopleistocene deposits and new mammalian find-localities of Northern Mongolia. 1974;1: 357-363.

103. Ruez DR, Gensler PA. An unexpected early record of Mictomys Vetus (Arvicolinae, Rodentia) from the Blancan (Pliocene) Glenns Ferry Formation, Hagerman Fossil Beds National Monument, Idaho. J Paleontol. 2008;82: 638-642. doi:10.1666/06-098.1

104. Fejfar O, Repenning CA. The ancestors of the lemmings (Lemmini, Arvicolinae, Cricetidae, Rodentia) in the early Pliocene of Wölfersheim near Frankfurt am Main; Germany. Senckenberg Lethaea. 1998;77: 161-193.

105. Zazhigin VS, Zykin VS. Novye dannye po stratigrafii pliotsena yuga Zapadno-Sibirskoi ravniny. Stratigrafiya pogranichnykh otlozhenii neogena i antropogena Sibiri. Novosibirsk: Inst. geologii i geofiziki SO AN SSSR; 1984. pp. 29-53. 
106. Repenning CA. Beringian climate during intercontinental dispersal: a mouse eye view. Quat Sci Rev. 2001;20: 25-40. doi:10.1016/S0277-3791(00)00133-5

107. Zazhigin V. Late Pliocene and Anthropogene rodents of the south of Western Siberia. Acad Sci USSR Trans. 1980;339: 1-156.

108. Repenning CA. Allophaiomys and the age of the Olyor Suite, Krestovka sections, Yakutia. US Government Printing Office; 1992.

109. Cuenca-Bescós G, López-García JM, Galindo-Pellicena MA, García-Perea R, Gisbert J, Rofes J, et al. Pleistocene history of Iberomys, an endangered endemic rodent from southwestern Europe. Integr Zool. 2014;9: 481-497. doi:10.1111/1749-4877.12053

110. Cuenca Bescós G, Laplana C. Evolución de Iberomys (Arvicolidae, Rodentia, Mammalia) durante el Cuaternario español. XI Jorn Paleontol. 1995; 69-72.

111. Paupério J, Herman JS, Melo-Ferreira J, Jaarola M, Alves PC, Searle JB. Cryptic speciation in the field vole: a multilocus approach confirms three highly divergent lineages in Eurasia. Mol Ecol. 2012;21: 6015-6032. doi:10.1111/mec.12024

112. Tesakov AS. Biostratigraphy of Middle Pliocene - Early Pleistocene of southern part of Eastern Europe (based on small mammals). Moscow: Nauka; 2004.

113. Agadjanian AK. Pliocene-Pleistocene Small Mammals of the Russian Plain. Nauka; 2009.

114. Ivanova VV, Erbajeva MA, Shchetnikov AA, Kazansky AY, Matasova GG, Alexeeva NV, et al. Tologoi key section: A unique archive for pliocene-pleistocene paleoenvironment dynamics of Transbaikalia, Bikal rift zone. Quat Int. 2019;519: 58-73. doi:10.1016/j.quaint.2018.11.004

115. Liu S, Jin W, Liu Y, Murphy RW, Lv B, Hao H, et al. Taxonomic position of Chinese voles of the tribe Arvicolini and the description of 2 new species from Xizang, China. J Mammal. 2017;98: 166-182. doi:10.1093/jmammal/gyw170 
116. Haslauer R. Microtus juldaschi. In: Wilson DE, Lacher TEJr, Mittermeier RA, editors. Handbook of the Mammals of the World. Barcelona: Lynx Edicions; 2019. p. 332.

S1 Table. Material, GenBank accession numbers and mitogenome characteristics.

S2 Table. Completeness of analyzed mitogenomes. Mitogenomes obtained in the current study are marked in bold, partial genes colored by yellow. Absent genes indicated with red color. The length of protein-coding genes is given in nucleotides.

S3 Table. Fossil calibrations used in dating analysis. Node labels correspond to Fig 2, ages are given in million years ago (Ma). FAD - age of the first appearance of the taxon in the fossil record (first appearance date).

S1 Fig. Nucleotide misincorporations at 5'-termini (A) and 3'-termini (B) of the Lemmiscus curtatus calculated using mapDamage. All possible misincorporations are plotted in gray, except for guanine to adenine ( $\mathrm{G}>\mathrm{A}$, blue lines) and cytosine to thymine ( $\mathrm{C}>\mathrm{T}$, red lines).

S4 Table. Test of substitution saturation. Analysis performed on all sites for $1 \& 2$ nd and 3 rd codon position separately. Iss - index of substitution saturationIssSym is Iss.c assuming a symmetrical topology, IssAsym is Iss.c assuming an asymmetrical topology, NumOTU - number of operation taxonomic units. Red color indicates P-value $<0.05$.

S1 File. Maximum likelihood phylogenies and saturation plots for each PCG. Species belonging to the tribes is marked with colours (Arvicolini - light blue, Lagurini - blue, Ellobiusini - purple, Clethrionomyini - magenta, Dicrostonychini - dark green, Ondatrini - light green, Prometheomyini - 
1013 yellow, Lemmini - red, nomen nudum species - black). Node labels display ultrafast ML bootstrap above

$101450 \%$. At the saturation plots colours mark the following partitions: 1st codon position transitions (ts) -

1015 brown, 1 st transversions (tv) - red, 2nd ts - blue, 2nd tv - green, 3rd ts - pink, 3rd tv - black.

1016 S2 File. The proposed system of generic group taxa within the tribe Arvicolini sensu stricto. 

Enscocapillus

L.trimucronatus •

H.fertilis •

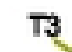

A.montensis ${ }^{45}$

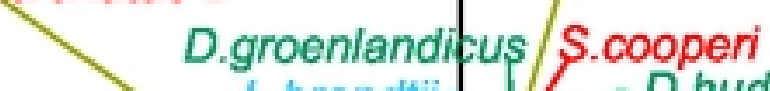

L.groenlandifus S.cooperi

1.5

iorquatus N.iren

A.tuvinicus

- E.lutescens D.bogdanovi a A strelzowi

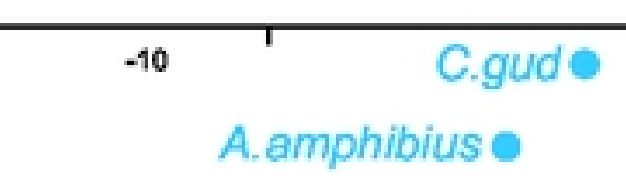

P.intermedius •

P.megalops $\bullet$

O.zibethicus •

Dicrostonychini

- Ellobiusini

- Lagurini

- Lemmini

- Ondatrini

- incertae sedis

- outgroup

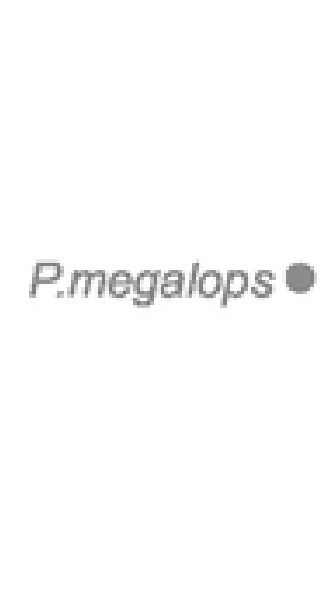

\section{figure1}

E.luteus O M.californicus

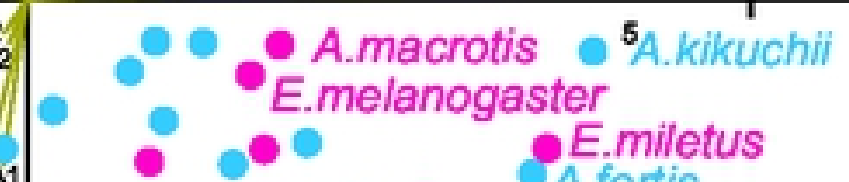

inensis $\bullet \bullet$ A.lemminus

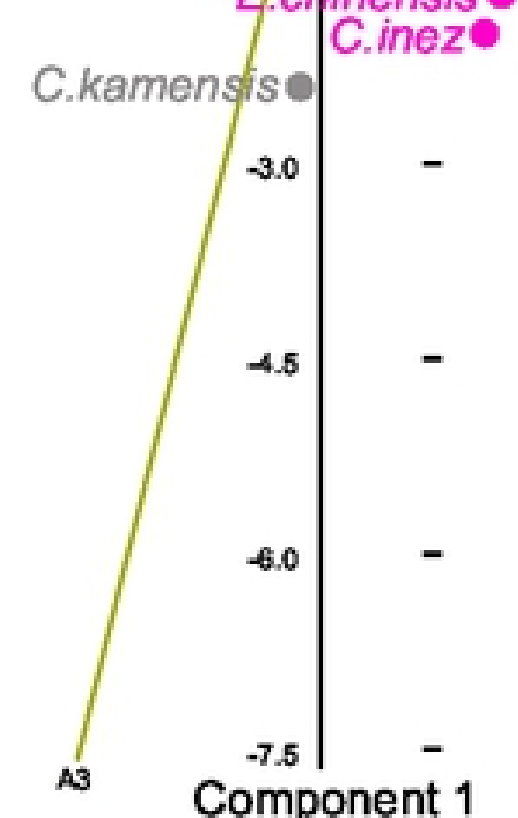




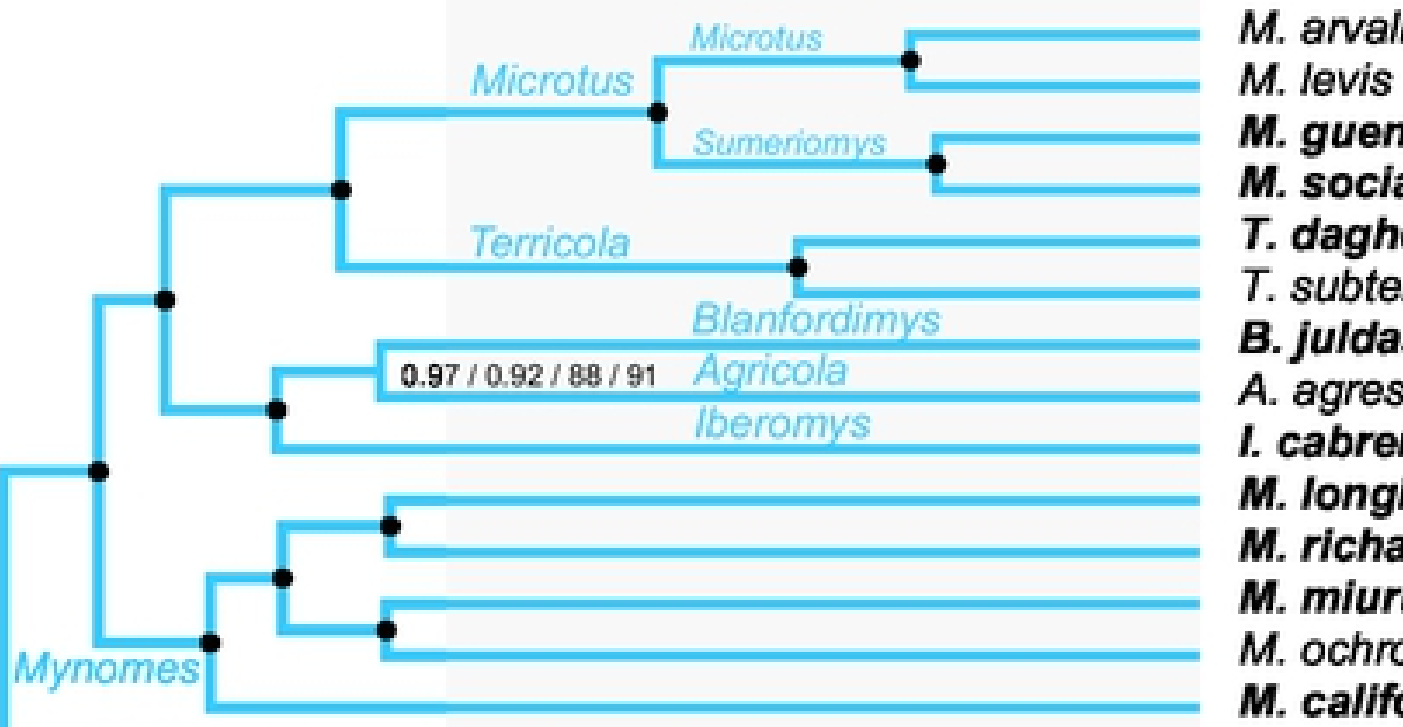

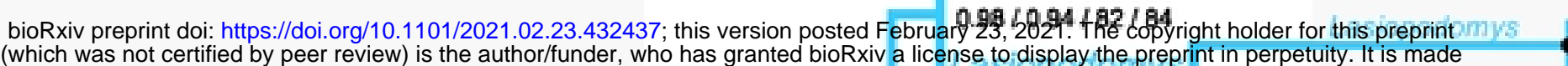

M. anvalis

$M$. levis

M. guentheri

M. socialls

T. daghestanicus

T. subterraneus

B. juldaschi

A. agrestis

I. cabrerae

M. longicaudus

M. richardsoni

M. miurus

M. ochrogaster

$M$. californicus

a dicense to display the preprint in

L. brandtii

L. mandarinus

L. gregalis

L. raddei

A. fortis

A. kikuchii

N. fuscus

$N$. irene

N. sikimensis

$P$. liangshanensis

C. gud

C. nivalis

L. curtatus

$H$. fertilis

L. lagurus

E. Iuteus

A. amphibius

E. fuscocapillus

E. lutescens

E. talpinus

D. bogdanovi

$0.98 / 0.96 / 44 / 50$

(20)

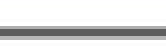

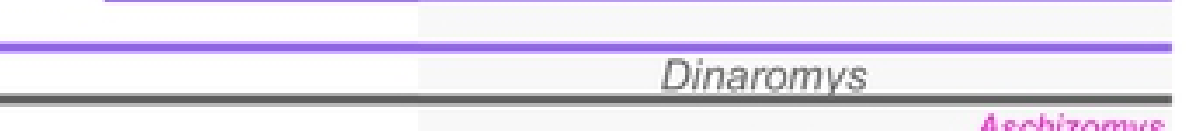

$0.92 / 0.94 / 65 / 82$

$0.73 / 0.91 / 64 / 73$

CLETHRIONOMYINI

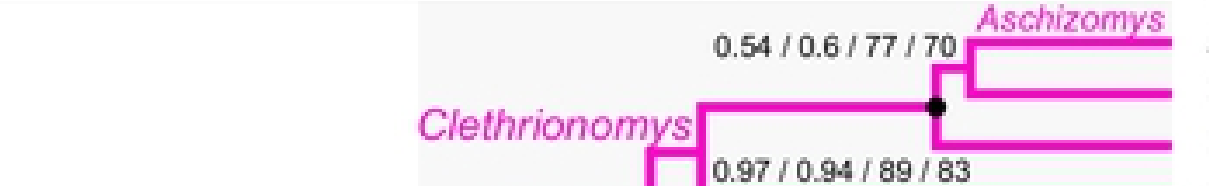

$0.97 / 0.94 / 89 / 83$

Aschizomys

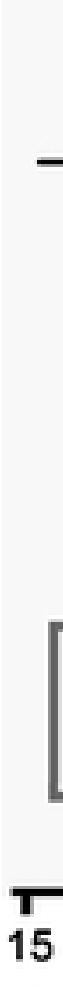

-

15
15

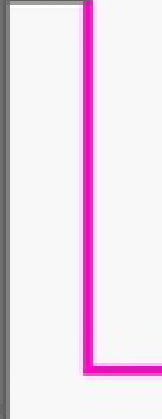

1.0

$-$

A
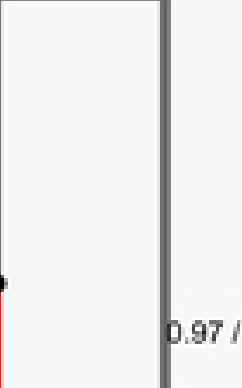

10.93/74/79

D.97/0.57/84/67

C ONDATRINI

$$
\text { DL. }
$$

LEMMINI

\section{B}
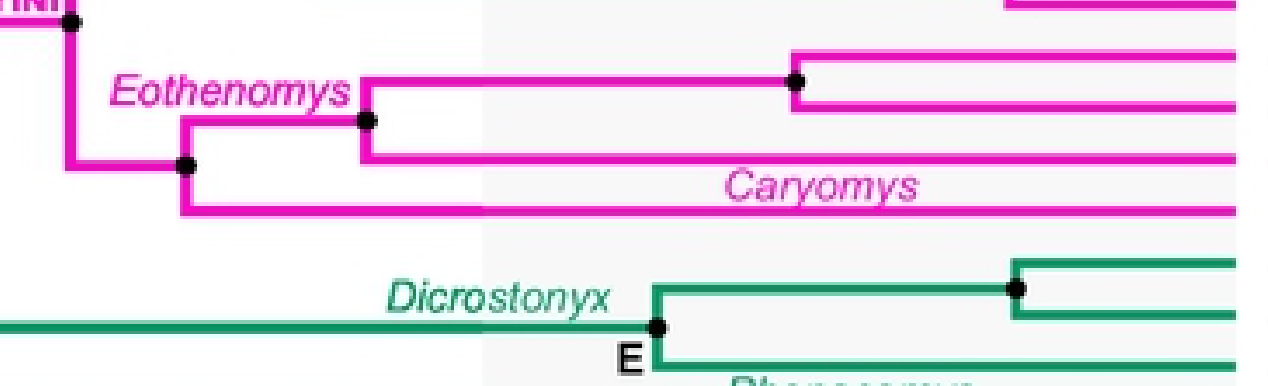

Phenacomys

Prometh

Lemmus

Myopus

Synaptomys

figure2

A. macrotis

C. centralis

C. glareolus

C. rutilus

A. lemminus

A. olchonensis

A. strelzowi

A. tuvinicus

C. regulus

C. rufocanus

E. melanogaster

E. miletus

E. chinensis

C. inez

D. groenlandicus

D. hudsonius

D. torquatus

$P$. intermedius

O. zibethicus

P. schaposchnikowi

L. trimucronatus

M. schisticolor

S. cooperi

Cricetulus

P. megalops

A. montensis 